\title{
Comparative Study for Trends of Solving Single Source Shortest Path Problems
}

\author{
Nilanshi Nigam \\ Student \\ Dr A.P.J A.K Technical \\ University,Lucknow,India
}

\author{
Vivek Bhushan Tiwari \\ Student \\ Dr A.P.J A.K Technical \\ University,Lucknow,India
}

\author{
Abdul Muttalib Khan \\ Student \\ Dr A.P.J A.K Technical \\ University,Lucknow,India
}

\begin{abstract}
As the name suggests, Single source shortest path is a technique to find the shortest path corresponding to a source vertex. Single source can be implemented using greedy and dynamic approach. There are many approaches proposed for the same. The idea is to minimize the complexity of the algorithm. This paper presents a review of different algorithm proposed for this technique and compares the complexity and efficiency of each approach . It analyzes each algorithm and takes into account the different parameters involved and hence provide an overview of it. It helps us to know various advantages proposed by different algorithm.
\end{abstract}

\section{Keywords}

Single Source Shortest Path(SSSP), Li-Qi(LQ), SIMD(Simple Instruction Multiple Data), SPFA(Shortest Path Faster Algorithm), Algebraic Decision Diagram(ADD).

\section{INTRODUCTION}

Single Source Shortest Path is a trend for analysing shortest path from a given single origin vertex in directed, undirected, mixed graphs. In a graph each edge is associated with some weight these weights represent the cost of travelling that particular edge, the minimum cost for travelling the particular destination represents SSSP. The sum of the weights are done and then the minimum sum is considered. Such path having minimum weight is said to be the shortest path. The most common algorithm for accomplishing the following task is Dijkstra algorithm but here various algorithms are discussed which vanishes the drawbacks of Dijkstra like use of negative weights and traversal of large graphs. There are various algorithms which explain the various method and thereby comparison is provided in this paper for easy accessibility and betterment in future work. Various experimentation came into existence and thereby given different results which made the task more.

\section{CATALOGUED WORK}

The following analysis is made after the study of various algorithms and various behavioral facts of the algorithms are stated below to find the Single Source Shortest Path in graphs.

J. A. Yang, D. C. Zhang and P.R. China, 'The Replicated Data Algorithm for determining the Single Source Shortest Path Problem' which is presented on ieeeexplore.org- in this paper, author throws light on the concept of data parallel algorithm and a replicated data algorithm for computing the Single Source Shortest Paths(SSSP) and also on the speed up computation of data replication technique over data parallel technique. The author explains that the capacity of storing data in Adjacency List is less as compared to that of Adjacency Matrix as the required storage in list is less than that of matrix. Hence the preference is given to the adjacency list due to SIMD arrays. Various algorithms were explained which concluded that when whole program is iterated in single step for one iteration, new path is evaluated for a new vertex. The following paper states that in Data Replicated Technique speed for implementation reduces to $S=K 1 * D /(K 2$ $+\log \mathrm{D})$.Hence on the basis of 2D,3D mesh and hypercube analysis its concluded that large problems in graph theory can easily be solved by replicated technique.The speedup computation analysis stated the same.

Pritam Roy, 'A New Memetic Algorithm with GA Crossover Technique to analyse Single Source Shortest Path (SSSP) problem' which is presented on ieeexplore.org- in this paper, author talks about the problem of finding the Single Source Shortest Path(SSSP), Modified Shuffled Frog Leaping Algorithm for solving the (MSFLA)with GA.This paper points out the disadvantages of Dijkstra and Bellman Ford Algorithm. It states that they cannot be used for negative weight edges in graph and also require complex computations for Real time Communication. MSFLA combines both the advantages and characteristics of Memetic Algorithm(MA) and Particle Swarm Optimisation(PSO). The advantage of MSFLA over other algorithm such as Dijkstra's Shortest Path Algorithm, Genetic Algorithm (GA), and Ant Colony Optimization(ACO) is that it enhances the optimization speed and provides accurate results in minimum iteration in a very short period of time. MSFLA with GA crossover helps to determine an exact solution at cost of an admissible C.P.U time.Hence MSFLA should be used as it is more reliable and less time taking and provides the best outcome as compared to other algorithms.

Suranga Chandima Nanayakkara, Dipti Srinivasan, Lai Wei Lup Xavier German, Elizabeth Taylor and S.H. Ong presented, ' Genetic Algorithm Based Route Planner for Large Urban Street Networks' which is presented on ieeeexplore.org- in this paper, author states development of Genetic Algorithm(GA) also known as route planning algorithm works on more than thousands of nodes in a graph. Hence the following outcomes are presented when Pure and Modified ANT Based Route Planning Algorithm are compared.This proposed GA route planner is thereby implemented in a multithreaded programming platform LabVIEW which makes the implementation time of GA much faster and provides a real time graph to show variation in fitness. This paper depicts the use of Proposed GA over Ant Based Algorithm and concludes thats proposed GA can find better shortest path as compared to Ant Based. Thereby it concludes that Modified ant based can provide equally good result than that of proposed GA but also stated the fact that Ant Based Algorithm is not original i.e. biased as it modifies the result with the help of Dijkstra's Algorithm as at first Dijkstra is performed then Ant based hence takes more time for computation. Hence GA is more general and efficient and therefore do more intelligent route planning.

Yusi Wei and Shojiro Tanaka. 'An Improved Thorup Shortest Paths Algorithm with a Modified Component Tree' which is 
presented on ieeexplore.org- in this paper, author enlightened about the new modified Thorup algorithm which reduces the cost of time from $75.01 \%$ to $58.26 \%$ and gives a far better result as compared to original Thorup and Fibonacci-based Dijkstra algorithm. Thorup Algorithm works on non-directed graphs comprising non-negative weights and helps in construction of minimum spanning tree. this method overcome the problem of sorting in Priority Queue based Algorithm. The problem of unvisited data structure is solved by improved Thorup algorithm by avoiding it. Thus it saves the time cost for the construction of unvisited structure and enhances the processing time for calculating shortest path. Hence to overcome the problem of unvisited data structure improved Thorup algorithm is used as it cost less time but its drawback is that it is slower than array based Dijkstra algorithm.

Zhishuai Sun, Zheng Xie, Li Dai and Zhi Chen, 'An Algorithm for the Shortest Pairs of Arc-Disjoint Paths Problem' which is presented on ieeeexplore.org-in this paper author, helps us to know the concept of routing system in multipath graphs through Shortest Pairs of Arc-Disjoint $\mathrm{P}$ aths Problem (SADPP) algorithm for disjoint paths. Here SPFA algorithm is used to analyse shortest path which uses the concept of adjacency list and Queue(FIFO). Time complexity for implementing SPFA algorithm $(\mathrm{O}(\mathrm{N}))$ is less as compared

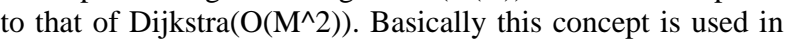
satellite networking. The author further explains that SADPP changes from time to time and therefore the shortest path is the one which takes less time. Shortest Path algorithm in Time Dependent Networks (SPTDN)algorithm is a pseudo Polynomial algorithm having complexity $\left(\left(\mathrm{O}\left(\mathrm{mn} \quad \mathrm{M}^{\wedge} 2\right.\right.\right.$ $\mathrm{C}))$ ). Hence SADPP is very useful in various fields like computer and satellite networks. Thus author indicates that SADPP is NP hard and sinks when it is not single thereby some other algorithms can come into existence for proper functioning.

Helmi Md Rais, Zulaiha Ali Othman, Abdul Razak Hamdan , 'Reducing Iteration Using Candidate List' which is presented on ieeexplore.org- in this paper author, states about an algorithm to overcome the problem of consumption of time and proper decision making with the help of Dynamic Ant Colony System (DACS) which stated that all the cities in the graph should be interconnected at each should be visited once. This is illustrated with the help of DACS3 experiment. This experiment illustrated the behaviour of Ants i.e. if there is an obstacle in the path of an Ant then it thereby finds an alternative path. the following algorithm has been already tested on various benchmarks like Microsoft visual $\mathrm{C}++$. The following experiment shows it uses less iteration time and finds the minimum shortest distance. Hence just by making few changes in the following algorithm the various properties can be enhanced for finding betters and comprehended solution for solving the shortest path problems in the graphs. Tianrui Li, Luole Qi, Da Ruan, 'An Efficient Algorithm for the Single-Source Shortest Path Problem in Graph' which is presented on ieeeexplore.org-in this paper author, present an efficient algorithm, Li-Qi (LQ) is proposing the concept of single source shortest path to find a simple path of minimum total weight from a origin vertex to each vertex present in a graph. It is based on the idea of queue \& relaxation. In this algorithm all the vertices are enqueued once and then they are selected for relaxation separately. And the algorithm terminates when the queue is empty. Complexity of LQ is less than that of Bellman, Dijkstra. In terms of time all other algorithm takes repetitive number of iteration for same vertices whereas LQ employs a queue to store only relaxed edges. LQ algorithm can also used for single source shortest path on graphs comprising negative weights.

JinFu Leng and Wen Zeng, introduced 'An Improved Shortest Path Algorithm for Computing One-to-one Shortest Paths On Road Networks' which is presented on ieeeexplore.org-in this paper author, present an algorithm which helps in the computation of one to one shortest path on road networks named as MILD TWO-Q it trace the minimum number of labels inside the two queue and thereby sorting the candidates nodes and terminating once the larger than the minimum labels which is more efficient than the algorithm which was earlier proposed by Palatino. According to Palatino's graph growth algorithm commonly named as TWO-Q . TWO-Q as a label correcting shortest path algorithm, TWO-Q algorithm trace from the origin node and travels the whole network before it gets the final result, it does not depend on the distance of the destination. It spent a lot of time on useless work when the shortest path is relatively short.

R. Iris Bahar, Gary D. Hachtel, Enrico Macii, Abelardo Pardo, Massimo Poncino and Fabio Somenzi introduced 'An ADDBased Algorithm for Shortest Path Back-Tracing of Large Graphs' which is presented on ieeeexplore.org- in this paper author, tells about an Algebraic Decision Diagram-based algorithm that implicitly determines shortest path backtracing. However we have symbolic shortest path algorithm which efficiently determines the weight of shortest path between the pair of vertices of graph but it do not keeps the sequence of vertex forming path. Whereas ADD algorithm consist of adjacency matrix of the graph which determines all pair of shortest path between source and destination and the symbolic procedure is based on triangulation rule. There were many more algorithm such as Dijkstra's and bellman-ford etc which efficiently determine shortest path which is based on traditional techniques such as matrix multiplication but the major demerits of these algorithm is the size of graph whereas ADD based algorithm can compute 1027 edges and 1036 vertices. Hence high compactness and the faster calculation of shortest path in case of higher size graphs makes ADD as an efficient algorithm.

Afshin Ghanizadeh, Saman Sinaie, Amir Atapour Abarghouei, and Siti Mariyam Shamsuddin, introduced 'A Fuzzy-Particle Swarm Optimization Based Algorithm for Solving Shortest Path Problem' that is presented on ieeexplore.org.-in this paper author, states about hybrid fuzzy- Particle Swarm Optimization (PSO) algorithm which is based on fuzzy logic for evaluating Single Source Shortest Path which has a greater use in improving the routing in multi-hop communication networks whereas as Particle Swarm Optimization(PSO) relay on social behaviour of flocks of birds and schools of fish ,but it falls into the trap of local optimum and converges slowly whereas in hybrid fuzzy PSO inertia weight whose right value prevent the search from falling in the trap of local optima which is evaluated by fuzzy rules. Hybrid fuzzy PSO has also an asset of encording mechanism of PSO. These modification improves the performing rate of algorithm by increasing it to 0.99 .

\section{ANALOGIZING BUREAU}

On the basis of analysis of the research papers the following table showcases the description and advantages of various algorithms which help to choose best among them. 
Table 1: Comparison between various algorithms.

\begin{tabular}{|c|c|c|}
\hline $\begin{array}{l}\text { Name of } \\
\text { algorithm }\end{array}$ & Description & Advantages \\
\hline $\begin{array}{l}\text { Algebraic } \\
\text { Decision } \\
\text { Diagram Based } \\
\text { Algorithm }\end{array}$ & $\begin{array}{l}\text { Algebraic } \\
\text { Decision Diagram- } \\
\text { based algorithm } \\
\text { helps in executing } \\
\text { shortest path back- } \\
\text { tracing. This } \\
\text { algorithm } \\
\text { comprises of } \\
\text { adjacency matrix } \\
\text { of graph which } \\
\text { determines all pair } \\
\text { of shortest path } \\
\text { between source and } \\
\text { destination and the } \\
\text { symbolic procedure } \\
\text { is based on } \\
\text { triangulation rule. }\end{array}$ & $\begin{array}{l}\text { This algorithm can } \\
\text { compute } 1027 \\
\text { edges and } 1036 \\
\text { vertices. Hence } \\
\text { high compactness, } \\
\text { faster calculation } \\
\text { of shortest path } \\
\text { also in case of } \\
\text { higher size. }\end{array}$ \\
\hline $\begin{array}{l}\text { MILD TWO-Q } \\
\text { algorithm }\end{array}$ & $\begin{array}{l}\text { This an algorithm } \\
\text { for computing one } \\
\text { to one shortest path } \\
\text { on road networks } \\
\text { named as MILD } \\
\text { TWO-Q it trace the } \\
\text { minimum number } \\
\text { of labels inside the } \\
\text { two queue by } \\
\text { sorting the } \\
\text { candidates nodes } \\
\text { and by terminating } \\
\text { larger than the } \\
\text { minimum labels. }\end{array}$ & $\begin{array}{l}\text { It terminates once } \\
\text { the larger than the } \\
\text { minimum labels. } \\
\text { Hence the } \\
\text { complexity is } \\
\text { reduced in terms } \\
\text { of time. }\end{array}$ \\
\hline $\begin{array}{l}\text { Li- } \\
\text { Qi(LQ)Algorith } \\
\text { m }\end{array}$ & $\begin{array}{l}\text { Li-Qi (LQ) is } \\
\text { proposed for single } \\
\text { source shortest } \\
\text { path to find a path } \\
\text { having minimum } \\
\text { weight from origin } \\
\text { vertex to all other } \\
\text { vertices. It is based } \\
\text { on the idea of } \\
\text { queue \& relaxation. } \\
\text { In this algorithm all } \\
\text { the vertices are } \\
\text { enqueued once and } \\
\text { then they are } \\
\text { selected for } \\
\text { relaxation } \\
\text { separately and } \\
\text { when the queue is } \\
\text { empty the } \\
\text { algorithm } \\
\text { terminates. }\end{array}$ & $\begin{array}{l}\text { Complexity of LQ } \\
\text { is less in terms of } \\
\text { time compared to } \\
\text { all other algorithm } \\
\text { as others takes } \\
\text { repetitive number } \\
\text { of iteration for } \\
\text { same vertices } \\
\text { whereas LQ } \\
\text { employs a queue } \\
\text { to store only } \\
\text { relaxed edges.LQ } \\
\text { algorithm can also } \\
\text { used for single } \\
\text { source shortest } \\
\text { path on graphs } \\
\text { comprising } \\
\text { negative weights. }\end{array}$ \\
\hline The Replicated & Replicated data & Large problems in \\
\hline
\end{tabular}

\begin{tabular}{|c|c|c|}
\hline Data Algorithm & $\begin{array}{l}\text { algorithm is used } \\
\text { for computing the } \\
\text { Single Source } \\
\text { Shortest Paths } \\
\text { (SSSP) also for } \\
\text { speeding up the } \\
\text { computation of } \\
\text { data replication } \\
\text { technique. It } \\
\text { explains that the } \\
\text { data storage in } \\
\text { Adjacency List is } \\
\text { less as compared to } \\
\text { that of Adjacency } \\
\text { Matrix as the } \\
\text { required storage in } \\
\text { list is less than that } \\
\text { of matrix. Hence } \\
\text { the preference is } \\
\text { given to the } \\
\text { adjacency list due } \\
\text { to SIMD [Simple } \\
\text { Instruction } \\
\text { Multiple Data] } \\
\text { arrays. When } \\
\text { whole program is } \\
\text { iterated in single } \\
\text { step for one } \\
\text { iteration, new path } \\
\text { is evaluated for a } \\
\text { new vertex. }\end{array}$ & $\begin{array}{l}\text { graph theory can } \\
\text { be easily be solved } \\
\text { by replicated } \\
\text { technique by the } \\
\text { speedup } \\
\text { computation } \\
\text { analysis. }\end{array}$ \\
\hline $\begin{array}{l}\text { Genetic } \\
\text { Algorithm Based } \\
\text { Route Planner }\end{array}$ & $\begin{array}{l}\text { Genetic Algorithm } \\
\text { (GA) based route } \\
\text { planning algorithm } \\
\text { that can work on } \\
\text { more than } \\
\text { thousands of nodes } \\
\text { in a graph. } \\
\text { Outcomes are } \\
\text { listed and } \\
\text { compared with } \\
\text { Pure and Modified } \\
\text { ANT Based Route } \\
\text { Planning } \\
\text { Algorithm. This } \\
\text { proposed GA route } \\
\text { planner is thereby } \\
\text { implemented in a } \\
\text { multithreaded } \\
\text { programming } \\
\text { platform Lab } \\
\text { VIEW which } \\
\text { makes the time } \\
\text { taken for } \\
\text { implementing GA } \\
\text { much faster and } \\
\text { provides a real time }\end{array}$ & $\begin{array}{l}\text { It takes less time } \\
\text { for computation. } \\
\text { Because as Ant } \\
\text { Based Algorithm } \\
\text { is based as it } \\
\text { modifies the result } \\
\text { with the help of } \\
\text { Dijkstra's } \\
\text { Algorithm i.e. at } \\
\text { first Dijkstra is } \\
\text { performed \& then } \\
\text { Ant based } \\
\text { Algorithm. }\end{array}$ \\
\hline
\end{tabular}




\begin{tabular}{|c|c|c|}
\hline & $\begin{array}{l}\text { graph to show } \\
\text { variation in fitness. }\end{array}$ & \\
\hline $\begin{array}{l}\text { An Improved } \\
\text { Thorup Shortest } \\
\text { Path Algorithm }\end{array}$ & $\begin{array}{l}\text { Thorup algorithm } \\
\text { reduces the cost of } \\
\text { time from } 75.01 \% \\
\text { to } 58.26 \% \text { and } \\
\text { gave a far better } \\
\text { result. Thorup } \\
\text { Algorithm works } \\
\text { on undirected } \\
\text { graphs with non- } \\
\text { negative weights } \\
\text { and helps in } \\
\text { construction of } \\
\text { minimum spanning } \\
\text { tree. }\end{array}$ & $\begin{array}{l}\text { This method } \\
\text { overcome the } \\
\text { problem of sorting } \\
\text { in Priority Queue } \\
\text { based Algorithm. } \\
\text { The problem of } \\
\text { unvisited data } \\
\text { structure is solved } \\
\text { al by avoiding it. } \\
\text { It saves the time } \\
\text { cost for the } \\
\text { construction of } \\
\text { unvisited structure } \\
\text { and enhances the } \\
\text { processing time } \\
\text { for calculating } \\
\text { shortest path. }\end{array}$ \\
\hline $\begin{array}{l}\text { Arc-Disjoint } \\
\text { Path }\end{array}$ & $\begin{array}{l}\text { Multipath routing } \\
\text { system through } \\
\text { Shortest Pairs of } \\
\text { Arc-Disjoint Paths } \\
\text { Problem (SADPP) } \\
\text { algorithm for } \\
\text { disjoint paths. Here } \\
\text { we use SPFA } \\
\text { algorithm to } \\
\text { analyse shortest } \\
\text { path which uses the } \\
\text { concept of } \\
\text { adjacency list and } \\
\text { Queue (FIFO). } \\
\text { Time complexity } \\
\text { of SPFA algorithm } \\
\text { (O(N)) is less. } \\
\text { Basically this } \\
\text { concept is used in } \\
\text { satellite } \\
\text { networking. It } \\
\text { further explains } \\
\text { that SADPP } \\
\text { changes at regular } \\
\text { intervals and } \\
\text { therefore the } \\
\text { shortest path is the } \\
\text { one which takes } \\
\text { less time. Shortest } \\
\text { Path algorithm in } \\
\text { Time Dependent } \\
\text { Networks } \\
\text { (SPTDN)algorithm } \\
\text { is a pseudo } \\
\text { Polynomial }\end{array}$ & $\begin{array}{l}\text { SADPP is very } \\
\text { useful in various } \\
\text { fields like } \\
\text { computer and } \\
\text { satellite networks. }\end{array}$ \\
\hline
\end{tabular}

\begin{tabular}{|c|c|c|}
\hline & $\begin{array}{l}\text { algorithm having } \\
\text { complexity ((O(mn } \\
\left.\left.\left.\mathrm{M}^{\wedge} 2 \mathrm{C}\right)\right)\right)\end{array}$ & \\
\hline $\begin{array}{l}\text { Reducing } \\
\text { Iteration Using } \\
\text { Candidate List }\end{array}$ & $\begin{array}{l}\text { It's an algorithm to } \\
\text { overcome the } \\
\text { problem of } \\
\text { consumption of } \\
\text { time and proper } \\
\text { decision making } \\
\text { with the help of } \\
\text { Dynamic Ant } \\
\text { Colony System } \\
\text { (DACS) which } \\
\text { stated that all the } \\
\text { cities in the graph } \\
\text { should be } \\
\text { interconnected at } \\
\text { each should be } \\
\text { visited once. This } \\
\text { is illustrated with } \\
\text { the help of DACS3 } \\
\text { experiment. The } \\
\text { further theory is } \\
\text { explained by } \\
\text { behavior of Ants } \\
\text { i.e. if there is an } \\
\text { obstacle in the path } \\
\text { of an Ant then it } \\
\text { thereby finds an } \\
\text { alternative path. } \\
\text { The following } \\
\text { algorithm has been } \\
\text { already tested on } \\
\text { various } \\
\text { benchmarks like } \\
\text { Microsoft visual } \\
\text { C++. The } \\
\text { following } \\
\text { experiment shows } \\
\text { it uses less iteration } \\
\text { time and finds the } \\
\text { minimum shortest } \\
\text { distance. }\end{array}$ & $\begin{array}{l}\text { Just by making } \\
\text { few changes in the } \\
\text { following } \\
\text { algorithm the } \\
\text { various properties } \\
\text { can be enhanced } \\
\text { for finding betters } \\
\text { and comprehended } \\
\text { solution to the } \\
\text { problem. }\end{array}$ \\
\hline $\begin{array}{l}\text { New Memetic } \\
\text { Algorithm with } \\
\text { GA Crossover } \\
\text { Technique }\end{array}$ & $\begin{array}{l}\text { Problem of finding } \\
\text { the Single Source } \\
\text { Shortest Path } \\
\text { (SSSP), Modified } \\
\text { Shuffled Frog } \\
\text { Leaping Algorithm } \\
\text { For solving the } \\
\text { MSFLA with GA } \\
\text { is introduced. It } \\
\text { points out the } \\
\text { disadvantages of } \\
\text { Dijkstra and } \\
\text { Bellman Ford } \\
\text { Algorithm. It states } \\
\text { that they cannot be } \\
\text { used for negative } \\
\text { weight edges in } \\
\text { graph and also } \\
\text { require complex } \\
\text { computations for } \\
\text { Real time } \\
\text { Communication. }\end{array}$ & $\begin{array}{l}\text { MSFLA should be } \\
\text { used as it is more } \\
\text { reliable and less } \\
\text { time taking and } \\
\text { provides the best } \\
\text { outcome as } \\
\text { compared to other } \\
\text { algorithms. }\end{array}$ \\
\hline
\end{tabular}




\begin{tabular}{|c|c|c|}
\hline & $\begin{array}{l}\text { MSFLA combines } \\
\text { both the } \\
\text { advantages and } \\
\text { properties of } \\
\text { Memetic } \\
\text { Algorithm (MA) } \\
\text { and Particle Swarm } \\
\text { Optimization } \\
\text { (PSO). Advantage } \\
\text { of MSFLA over } \\
\text { other algorithm for } \\
\text { example Dijktra's } \\
\text { Shortest Path } \\
\text { Algorithm, Genetic } \\
\text { Algorithm (GA), } \\
\text { Ant Colony } \\
\text { Optimization(ACO } \\
\text { ) i.e. it enhances } \\
\text { the optimization } \\
\text { speed and provides } \\
\text { accurate results in } \\
\text { minimum iteration } \\
\text { in a very short } \\
\text { period of time. } \\
\text { MSFLA with GA } \\
\text { crossover helps to } \\
\text { reach exact } \\
\text { solution in time } \\
\text { acceptable to } \\
\text { C.P.U. }\end{array}$ & \\
\hline $\begin{array}{l}\text { Hybrid Fuzzy } \\
\text { Particle Swarn } \\
\text { Optimization }\end{array}$ & $\begin{array}{l}\text { A hybrid fuzzy- } \\
\text { Particle Swarm } \\
\text { Optimization } \\
\text { (PSO) algorithm } \\
\text { based on fuzzy }\end{array}$ & $\begin{array}{l}\text { Particle Swarm } \\
\text { Optimization(PSO } \\
\text { ) converges slowly } \\
\text { as it falls into the } \\
\text { trap of local }\end{array}$ \\
\hline
\end{tabular}

\section{CONCLUSION}

Thereby it can be concluded that ADD can work on large graphs and MSFLA has very less time complexity to perform the task of finding SSSP. It also concluded that other algorithms like ADD,MSFLA and replicated data techniques are far better than Dijkstra algorithm on the basis of complexity and performance rate.

Thus, overall it can be concluded that MSFLA with GA crossover is one of the best algorithm on the scale of computation of speed to find SSSP on graphs while ADD covers all the advantages of MSFLA with addition to that it works efficiently on the larger graphs.

Dijkshtra algorithm can be improved if and only if the drawback of larger graphs could be solved. ADD can help in manipulating larger graphs in short span of time. If we further work upon the application of ADD then we could definitely reduce the cost of the flow in the graph.

\section{REFERENCES}

[1] A Yang, D. C. Zhang and P.R. China, 'The Replicated Data Algorithm for Solving the Single Source Shortest Path Problem'.

[2] Pritam Roy, "A New Memetic Algorithm with GA Crossover Technique to solve Single Source Shortest Path (SSSP) problem".

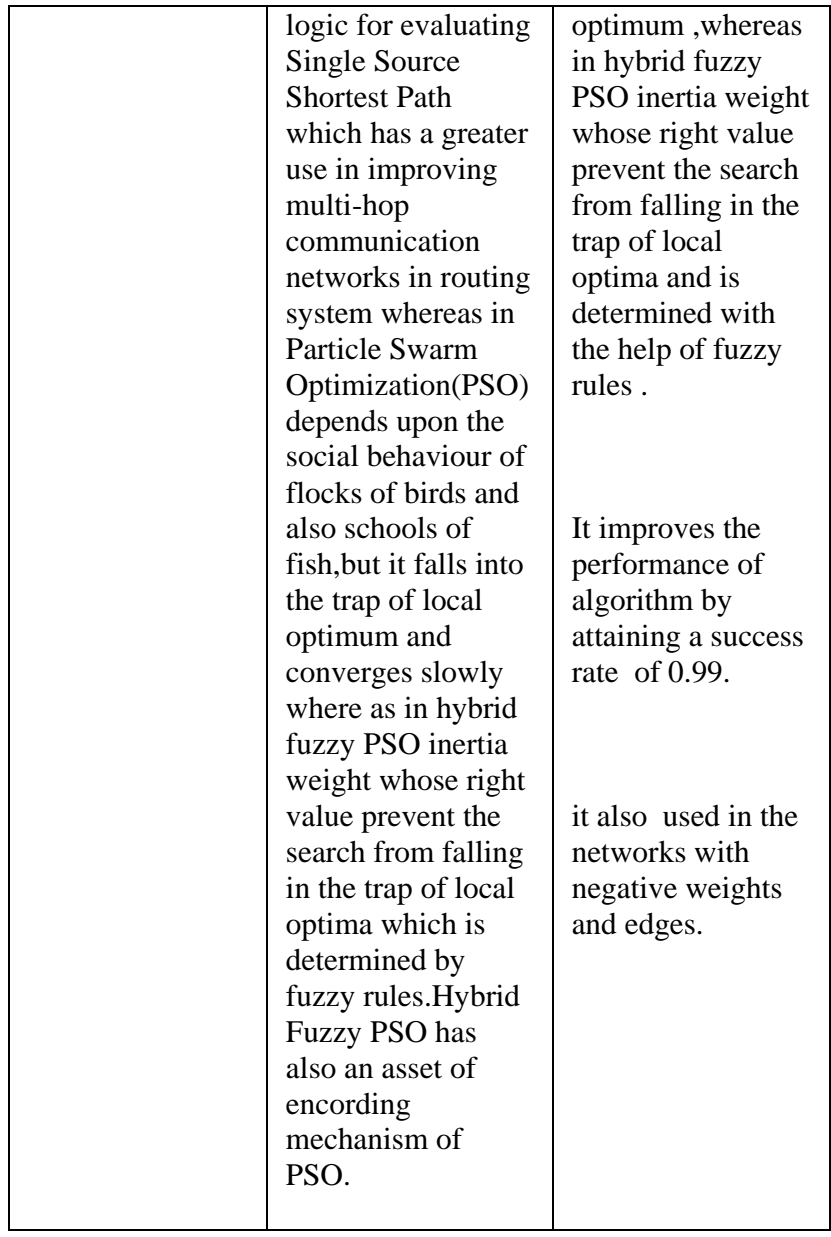

[3] Suranga Chandima Nanayakkara, Dipti Srinivasan, Lai Wei Lup Xavier German, Elizabeth Taylor and S.H. Ong, "Genetic Algorithm Based Route Planner for Large Urban Street Networks".

[4] Yusi Wei and Shojiro Tanaka. "An Improved Thorup Shortest Paths Algorithm with a Modified Component Tree".

[5] Zhishuai Sun, Zheng Xie, Li Dai and Zhi Chen, "An Algorithm for the Shortest Pairs of Arc-Disjoint Paths Problem".

[6] Helmi Md Rais, Zulaiha Ali Othman, Abdul Razak Hamdan, "Reducing Iteration Using Candidate List".

[7] Tianrui Li, Luole Qi, Da Ruan, "An Efficient Algorithm for the Single-Source Shortest Path Problem in Graph".

[8] JinFu Leng and Wen Zeng, "An Improved Shortest Path Algorithm for Computing One-to-one Shortest Paths On Road Networks".

[9] R. Iris Bahar, Gary D. Hachtel, Enrico Macii, Abelardo Pardo, Massimo Poncino and Fabio Somenzi. "An ADDBased Algorithm for Shortest Path Back-Tracing of Large Graph".

[10] Afshin Ghanizadeh, Saman Sinaie, Amir Atapour Abarghouei, and Siti Mariyam Shamsuddin, "A Fuzzy Particle Swarm Optimization Based Algorithm for Solving Shortest Path Problem". 